\title{
Mechanical and thermal properties of chemical treated kenaf fibres reinforced polyester composites.
}

\begin{abstract}
Kenaf fibre reinforced polyester biocomposites fabricated by hand lay-up technique by using propionic and succinic anhydride-modified kenaf fibres. Chemical structure, mechanical, thermal and morphological properties of kenaf fibres reinforced polyester biocomposites evaluated. The Fourier transform infrared study of modified kenaf fibres carried out to look at changes in functional groups after modification. It confirmed from Fourier transform infrared spectroscopy the variation in positions of functional groups. The mechanical (tensile, flexural and impact) property results revealed that biocomposites with modified kenaf fibres exhibited better properties as compared to untreated kenaf fibres-reinforced polyester biocomposites. Morphological studies show that treated kenaf biocomposites show better fibre/matrix interaction. Thermal analysis results of modified biocomposites exhibited higher initial and final decomposition temperatures. Modified biocomposites display less char residue as compared with unmodified kenaf fibres reinforced polyester composites.
\end{abstract}

Keyword: Fibres; Chemical treatments; Composites; Mechanical properties; Thermal properties. 